\title{
Leveraging nation branding opportunities through sport mega-events
}

\section{INTRODUCTION}

South Africa has faced branding challenges similar to most developing nations, given the unfamiliarity of its brand and also having potentially incorrect, out-dated or stereotyped associations. Furthermore, the "Brand Africa"/ continent brand effect often results in African nations being associated with the same attributes across the continent, such as crime, civil war, famine, disease and corruption (Anholt, 2007). In addition, heightened media attention on the nation in the lead up to the 2010 mega-event focused on many negative aspects such as inflation, crime and xenophobic riots (Tomlinson et al., 2009). As the largest sport event to be hosted on the African continent, the 2010 FIFA World Cup was perceived as an opportunity to dispel common stereotypes about Africa and dispel Afro-pessimism (Donaldson and Ferreira, 2009; Tomlinson et al., 2009). The local organising committee clearly stated the nation's intention to use the sport mega-event to transform these perceptions of the nation and thus develop its nation brand, as is evident in the following quotation by the $\mathrm{CEO}$ of the Organising Committee:

"[The World Cup] is about nation-building, it's about infrastructure improvement, it's about country branding, it's about repositioning, it's about improving the image of our country, and it's about tourism promotion," (Jordaan, as cited in Allmers and Maennig, 2009, p.500).

While a previous paper (reference omitted for blind review) described the nation branding opportunities created by the 2010 sport mega-event for the host nation, this paper explores the manner in which these opportunities can be leveraged by nation brand stakeholders.

\section{LITERATURE REVIEW}

\subsection{Nation branding and sport mega-events}

Fan (2010) defines nation branding as:

a process by which a nation's images can be created, monitored, evaluated and proactively managed in order to improve or enhance the country's reputation among a target international audience (p.101).

This definition stresses the process and actions of brand stakeholders and stresses the central activity of nation image management. It notes that nation brands are constructed and managed by stakeholders and don't simply come into existence on their own, and furthermore, that there is a strategic intentionality to the process, namely that it is expected to result in positive reputation.

The leadership and control of a nation brand is a particular challenge. According to Hankinson (2010), a nation brand is not owned or controlled by a single organisation, but rather jointly developed and delivered by a network of public and private sector organisations. Morgan et al., (2010, p.3) note a criticism of place branding being that "there are too many stakeholders and too little management control". Dinnie (2011, p.70) refered to the legitimacy of who manages a nation brand as an "ethical challenge". More broadly, Fan (2010, p.98) asserts that nation branding is concerned with "a country's whole image on the international stage, covering political, economic and cultural 
dimensions". This is similar to an early definition of nation branding by Anholt (2003, p.11), who likened it to a 'strategic vision', defining the activity of nation branding as:

"determining the most realistic, most competitive and most compelling strategic vision for the country, and ensuring that this vision is supported, reinforced and enriched by every act of communication between the country and the rest of the world".

The final aspect of this definition hints at the potential for nation branding that hosting a sport mega-event may hold for a nation as an "act of communication" with the world. Sport can be a powerful agent in the imaging, re-imaging and branding of places, especially through the hosting of sport mega-events (Getz, 2003; Higham and Hinch, 2009). While mega-events can include a variety of different types of events, there has been a growing awareness of the potentially significant impact that hosting sport megaevents, such as the Olympic Games and FIFA World Cup, can have on a country's brand image (Gibson et al., 2008). Sport mega-events have become increasingly important in the contemporary era, with their hosting becoming an object of policy for an increasing number of nation states in the world, most notably "as a means to gain international visibility in some ways" (Cornelissen, 2007, p.242). Sport mega-events represent a means of achieving international prominence and national prestige (Essex and Chalkley, 1998), or, as Berkowitz et al. (2007) put it, "a great branding opportunity" for nations (p.164).

Such events may provide an opportunity to create or promote an image and also re-brand a nation (Anholt, 2007; Florek and Insch, 2011). For example, the Olympic Games have long been used to serve the imaging or re-imaging of places (Higham and Hinch, 2009). Florek and Insch (2011) cite the case of Sydney and the Olympic Games of 2000 that accelerated the awareness of Australia as a destination by up to ten years while they also cite the case of Germany's image being "softened and boosted" through the hosting of the 2006 FIFA World Cup. Heslop et al. (2013, p.13) noted how increasingly emerging nations recognise are bidding for and hosting sport mega-events as "a fast-track to world recognition and reputation enhancement". The high media profile of mega-events has especially been emphasised as a means to increase the awareness, prominence and standing of places as well as serve as an agent of change in terms of imagery and place meaning (Chalip and Costa, 2005; Florek and Insch, 2011; Higham and Hinch, 2009).

\subsection{From mega-event impacts to "leveraging"}

Weed and Bull (2009) suggest that the event impacts framework may be outmoded and, supported by a number of other authors (Chalip, 2004; Dickinson and Shipway, 2007; Jago et al., 2010), indicated that a new focus with an emphasis on leveraging may be more applicable. According to Weed's $(2009$, p. 621) meta-review of sport tourism research, "the nascent literature around the strategic 'leveraging' of sports mega-events for specific purposes represents a welcome 'shift' from a dominant focus on measuring post-hoc impact assessments". Leverage rather broadly refers to "those activities... which seek to maximise the long-term benefits from events", and "the processes through which the benefits of investments are maximized" (Chalip, 2004, p.228). The focus on leveraging represents a shift to a more forward-thinking, proactive, strategic approach, acknowledging the vital role of stakeholders in the process. Smith (2014, p.15) reconceived mega-events as "windows of opportunity within which to undertake initiatives", describing leveraging as: 
an approach which views mega-events as a resource which can be levered to achieve outcomes which would not have happened automatically by staging an event (p.16).

The focus on leveraging therefore represents a shift to a more forward-thinking, proactive, strategic and tactical approach whre the objective is "to to identify strategies and tactics that can be implemented prior to and during an event in order to generate particular outcomes" (Chalip, 2004, p.228).

To date, however, few studies have captured the experiences, observations and lessons learned by event and brand stakeholders. Weed (2010) noted that knowledge relating to the perceptions of various stakeholders in sport and tourism, be they participants, policymakers, providers, host communities or the media, is limited. Grix (2012) produced a rare study that used Chalip's (2004) conceptualisation of 'leverage' to investigate the strategies used to leverage nation brand image legacies of the 2006 German FIFA World Cup. Grix explained that a key for Germany was that it planned meticulously in the lead up to the event, devising a number of campaigns targeted at different groups and including a wide array of partners from business, government, civil society, culture and sport. This study therefore aimed to address the question: How can stakeholders leverage and sustain a nation branding legacy from a sport mega-event for a host nation?

\section{METHODOLOGY}

The literature review noted a change in focus from event impact studies to a greater awareness of stakeholder activities involved in leveraging these impacts. An assessment of event leveraging can relate to short-term or immediate activities by event hosts or longterm activities, both before and after the event has taken place (Chalip, 2004). This study adopted a qualitative approach in order to ascertain key stakeholder experiences, perceptions and lessons learned relating to nation branding leveraging.

Firstly, a definitive set of stakeholders was selected, using the list of stakeholder types found in the literature. Further to this list, in the case of a sport mega-event, sport organisations, government agencies, event owners/ organisers, the media and host nation citizens can be added (Weed and Bull, 2009; Weed, 2010). The framework of power, urgency and legitimacy by Mitchell et al. (1997) was applied to these lists, clustering stakeholders according to their degree of power or influence in brand development; the degree of legitimacy or recognised authority or brand leadership that the stakeholder exhibits; and the extent to which the stakeholders had a measure of urgency or vested interest in the specific organisation and success of the FIFA event. The framework describes stakeholders that have high levels of each of these aspects as definitive stakeholders. Key informants were therefore purposively chosen to represent definitive stakeholders. For this study, the media and citizens were excluded from the potential respondents as this study focuses rather on the strategic and tactical approach of leveraging. The selection of definitive stakeholder sectors was identified as the following:

- Event 'owners' or rights holders, responsible for the national event organisation (i.e. FIFA OC);

- Regional government event management and strategic co-ordination;

- Host city (local government) event management and strategic co-ordination;

- National government agency for tourism promotion; 
- National government agency for nation branding (domestic and international);

- National government department for sport and recreation;

- Regional (Southern Africa) tourism destination promotion agency;

- Tourism destination promotion agency at a host city level;

- National tourism destination and services providers;

- Business and investment promotion agency at a host city level;

- Top-tier event sponsor

- Research co-ordination for sport event tourism and consultation at a national level; and

- National academic researchers in mega-event impacts and sport event tourism studies.

Key informants were therefore purposively chosen to represent definitive stakeholders. Furthermore, the researcher was a member of the '2010 Technical Update Committee' of the Provincial Government of the Western Cape (representing the regional academic sector and event-related research). This committee was formed in 2008 as a platform for communication and information dissemination between the major host city and provincial event and brand stakeholders within the Western Cape provincial region. The researcher used this database of stakeholders as a starting point for contacting representatives of the definitive stakeholder sectors identified. Five stakeholders were selected from this committee, namely: Provincial Government of the Western Cape; the City of Cape Town; Cape Town Tourism (local destination promotion agency); Accelerate Cape Town (local business and investment marketing organisation); and the Cape Higher Education Consortium (CHEC) that represented the local universities and event-related research coordination. These committee members assisted the researcher to source additional representatives at a national level and counterparts in other host cities across the country. Similar counterparts to these organisations were then included for the host cities of Johannesburg and Pretoria; Durban; and a smaller host city of Nelspruit ('Mbombela'). Representatives at a national level were included, namely the official "brand custodians" of the nation brand, "Brand South Africa"; and the national government departments of sport and tourism. Three additional tourism-specific stakeholders were included to represent the destination brand stakeholders, namely: the South African National Parks (SAN Parks) board that represents the game parks in the host nation; and the South African Tourism Services Association (a general representative of tourism services in the nation). A Regional tourism destination marketing organisation (RETOSA) was added to reflect the experiences of neighbouring nations. The research consultancy company employed by Tourism South Africa was included as their predictions and assessments pre and post the event were widely publicised and acknowledged. While all of the above have a recognised power, urgency and legitimacy in relation the nation brand and its related destination brands, two groups of stakeholders were specifically linked with the organisation of the event and the brand and co-branding link between the event and the host nation brand. These were: the national-level LOC and the event sponsors. Coca-Cola was selected as a sponsor to include, as they appeared to make additional efforts to link their brand with the event and national brand characteristics through their sponsorship leveraging activities.

In order to provide an informed external perspective of the 2010 event and its impact on the host nation brand as well as additional examples and experiences from other sport 
mega-events, the researcher selected a small number of key international informants who were not specifically involved in the 2010 FIFA World Cup to be interviewed. These respondents were regarded as mega-event or nation branding experts due to their experience in other mega-event contexts (such as Manchester 2006 Commonwealth Games; London 2012 Olympic Games; and Glasgow 2014 Commonwealth Games), or as consultants to nations and cities bidding to host mega-events, or regarded as leading academic researchers in this field of study. The selection of 'definitive' stakeholder sectors was identified (as displayed in Table 1) and potential respondents were identified to represent each sector.

\section{(Insert Table 1 here.)}

In total, 27 interviews were conducted with 19 brand and event stakeholders and an additional eight key informants/ experts, during the period March 2012 to November 2013. It was felt that this time period would allow the stakeholders to be more objective in their reflections and also to reflect on the post-event legacy and the degree to which the opportunities had been leveraged post the event. For each organisation selected, the researcher identified the most suitable candidate to be interviewed as the most senior member of the organisation or department that was directly involved in the 2010 event. The disclosure of respondent identities raises important ethical considerations for researchers. In this paper it was decided to keep the identities and specific organisation of the respondents confidential and the nature of the sector or organisation is only decribed where releveant to the discussion. Direct quotes reference a respondent number (e.g. R3) as a form of distinction only.

This sample size is regarded as large, especially for a mixed methods study, although still within an expected size range. For example, Grix's (2012) qualitative study already mentioned selected nine stakeholder respondents. In other broader place and destination branding stakeholder-related studies reviewed, up to 32 candidates (Marzano \& Scott 2009) were selected for in-depth interviews. Some authors recommend between 5 and 25 interviews (e.g. Creswell 2014). Others assert that you need to interview "as many individuals as necessary to find out what you need to know" (termed the "saturation" point), with this said to occur even within the first 12 interviews (Hanna \& Rowley 2013, p.1794). The reason for more than 12 interviews conducted in this study was so that the different brand and event stakeholder groupings that had been identified would be represented. Furthermore, it was also decided to add different viewpoints from stakeholders in smaller cities, neighbouring regions and sponsors, for example.

The experiences, lessons and insights from these subjects were elicited using in-depth, semi-structured interviews. The semi-structured interviews were guided by a set of questions related to topics identified through the literature. This interview protocol comprised of open-ended questions (e.g. 'How would you summarise the nation branding legacy that has been left by the event for the nation?'; 'Do you believe that there were any nation-branding opportunities lost or not utilised fully related to the event?'; and 'Do you believe that the nation-branding gains of 2010 are being leveraged post the event?'). The interviewer was able to probe or clarify issues raised and to explore particular areas of experience or expertise of the respondent. Face-to-face interviews were conducted with all except for three international interviews that were conducted by Skype. Due to the nature of the semi-structured interview, interview times varied per respondent, from 35 to 75 minutes in duration. The respondents were generally very responsive and supportive of the research process. Most indicated that it was useful to reflect on their experiences and pass on their observations and lessons learned, noting that there had not been many such opportunities to do so. This highlights the need to record the knowledge and experiences of mega-event stakeholders. 
The interviews were digitally recorded and manually transcribed, verbatim. The transcriptions were then analysed and manually coded using the software programme Atlas.ti. An inductive or 'bottom-up' approach to the coding was followed, with codes being developed from key words as each response was reviewed. From the resultant long list of codes, clusters or categories were developed.

\section{FINDINGS}

The respondents were generally very positive about the impact of the sport mega-event on the nation brand. Respondents provided many examples of activities and initiatives that they or others undertook that influneced these positive outcomes and also compared activities with those of other mega-events they were aware of. The analysis clustered the types of leveraging activities and examples given by the respondents into broader themes, thus revealing seven key focus areas that describe general types of leveraging activities for stakeholders to maximise and sustain the nation branding legacy from a sport megaevent (summarised in Table 2).

(Insert Table 2 here)

\subsection{Host the media \& embrace new media/ comunication forms:}

The media emerged as a crucial agent that "plays a huge role" (R5) in the formation of brand perceptions. Media exposure generated by the event was regarded as one of the most important brand development opportunities for the host nation. An assessment of the legacy that the media accounted for after the event was indicated as the fact that many journalists who would not have visited the nation had been able to do so and were therefore able to report more authentically and with a greater understanding of the nation's context.

The respondents gave some insights as to how South Africa and the United Kingdom took several actions that aimed to address media concerns and promote more authentic reporting for the 2010 FIFA World Cup and London Olympic Games. For both of these mega-events, there was a deliberate strategy and actions taken to "host" the media.

The foundations for the media relations were laid in the lead up to the 2010 mega-event. Local government authorities and tourism promotion agencies combined to create media tours, where selected key journalists from around the world were invited to the country to inspect the preparation for the 2010 event and also to acclimatise to the nation and assist them to write positive media reports in the lead up to the event. The following quotation explains the impact of this:

The media tours really helped a lot. The journalists we hosted in the country a

year before the World Cup really helped. The perceptions started changing (R4).

During the event period, some of the host cities created media centres, separate from the official FIFA media and broadcasting centres. These were to allow accredited and, more especially, non-accredited media persons a place to base themselves during the event, where they would have access to an office area, information and interviews pertaining to the event and the tourist destination and in some cases, special offers and excursions for media representatives. The mega-event attracted a large number of unaccredited media representing a diverse array of media forms, such as 'bloggers' and social media website journalists, who are usually not catered for through traditional media hosting 
mechanisms. The following quotation indicates the opportunities created through these media centres especially for the unaccredited, new media:

This [the media centre] provides a home for them. From there it gives them a place to work and us set up to facilitate their needs and stories suggested. ... It gives us a chance to talk to them, to brief them on non-sport matters (R12).

\subsection{Mobilise the internal brand support:}

The World Cup provided "an opportunity to portray a more positive image of the country both internally and externally" (R2). Besides the external brand component portrayed through the media, the impact of the event on the local population was described as of vital importance to the nation brand development, chiefly through fostering social cohesion and national pride or confidence. Focusing on the internal impacts on the brand, respondents noted the World Cup's influence on local residents, in terms of: increased sense of national pride; social cohesion; self-confidence; and a general "feel-good factor" (R2).

Showcasing happy, friendly, excited and united local citizens was also described as a crucial element in the portrayal of more authenitc nation brand imagery. The significance of this, especially in the case of South Africa, given its tumultuous political and social history, is explained in the quotation below:

For decades people only saw images of violence and crime so it was important to highlight the fun, the people and not the wildlife (R4).

What transpired during the event was that the world saw: "people celebrating in the street, people walking, people happy, people smiling" and "a fun, vibrant country that liked to party" (R1). The stakeholders clearly identified a close link between the internal brand and the overall nation brand development.

Although stakeholders don't have a great deal of control or influence over the degree of support shown by the local citizens, respondents mentioned a number of activities and campaigns that were implemented in the lead up to the event that were designed to activate and mobilise support, enthusiasm and national pride among the residents. Campaigns such as 'Fly the flag for South Africa' were directed at the local citizens, "to mobilize the nation to support the event" and "to promote South Africa as a positive brand" (R4). This campaign encouraged citizens to make the national flag prominent, to wear the national team colours, to learn the 'Diski' special dance created for the event and learn to sing the national anthem. Another campaign, 'Football Friday', promoted the wearing of the national team shirt on Fridays in the year leading up to the event. The following assessment of these activities was provided:

It was these kinds of fun things that got the country mobilised to demonstrate that we are proud to be South African. This is who we are: we're full of fun; we're very friendly. And I think the foreigners experienced that (R4).

\subsection{Co-create brand value through stakeholder partnerships:}


A number of stakeholders referred to the working relationship with other stakeholders as 'partnerships'. This indicates a close association between the entities, in order to achieve a set of common goals related to the opportunities created by the event. One stakeholder emphasised the importance of partnerships between different parties, insisting that his organisation looks for opportunities to partner with the rights holder, sponsors and the local organisers or host cities as they realise the potential of co-creating brand value:

Wherever there is opportunity for relationship we try build each other up (R27).

The stakeholders mentioned the improvement of relationships between private and public sectors, as well as the improved co-operation between different government levels and departments. In some instances, stakeholders noted difficulties and challenges working with different stakeholders, although these initial challenges were said to have improved over time, to a point where stakeholders expressed an intention for these partnerships to be sustained. In some instances, where there was initial conflict, a stakeholder needed to indicate how the cooperation between the parties would result in benefits for both.

An example was also given of different stakeholders collectively partnering to form an umbrella brand to achieve similar outcomes, in this case broadly leveraging the event opportunity to engage with the business and investment industry. This partnership was so successful that it has continued to operate the umbrella brand at other sport mega-events post 2010.

We knew there would be a whole lot of people, very powerful people, business people, coming on hospitality packages as guests of companies, sponsors etc. So we set up this place where visiting business people could be brought together with local business people. We created 'Connected Cape Town' that was an umbrella brand that covered [a range of stakeholders]. We all worked in partnership (R4).

\subsection{Create brand experiences \& engagement opportunities:}

Referring to the visitor experience, one stakeholder mentioned that during the event, "Everywhere you went people were having a good time" (R18). It was not just by chance that the experience was 'everywhere'. The rights holders worked together with the event management and host cities to create areas outside of the stadia for tourists and locals to enjoy the event experience in a more controlled manner. The official FIFA Fan Fests (fan parks) in each host city became places associated with the event experience, featuring live screenings of the matches combined with entertainment, food and beverages and other activities and experiences offered by official sponsors. The City of Cape Town extended the event experience further by creating a 'Fan Walk' that linked the fan park to the stadium and also to the main transportation hubs and prime tourist attractions in the vicinity. Essentially, the city created a $2,4 \mathrm{~km}$ route for the fans, tourists and locals, that combined walkways, footbridges and major roads (that were pedestrianised on match days) and were filled with a series of organised events, street performers and vendors. The combined result was "a spectacle of colour and spirit" that became a feature of the event experience in Cape Town in its own right (R10). These spaces extended the event experience and created innovative ways to experience the inner city.

The stakeholders also mentioned the importance of non event-specific tourism infrastructure and services as crucial to the tourist experience. Hotels and 
accommodation, public transport, airports and the availability of other tourist offerings and attractions (such as safari's) are all noted as part of this experience. Stakeholders confirmed that although the sport tourists may be in the nation primarily for the event, they are also interested in other more usual tourist activities and attractions. One stakeholder described these activities as the "mix of experiences" that forms a destination "package" (R3).

\subsection{Leverage the opportunity to showcase or create iconic brand elements:}

Stakeholders mentioned each of the following examples of brand elements that were showcased through the event, namely: physical urban iconic development (e.g. the new stadia and urban scenes during event broadcasts), geographic icons (e.g. the BBC media centre featured the natural backdrop of Table Mountain prominently in its media coverage from the city of Cape Town), cultural icons (e.g. national history and dance showcased during the opening ceremony) and even political or celebrity icons (e.g. Nelson Mandela paraded at the closing ceremony). Similarly, experts involved in the London 2012 Olympic Games explained how they showcased existing cultural or historical design icons through the sport event, for example, using the Horse Guard's Parade as the backdrop for the beach volleyball competition and Buckingham Palace as the backdrop for the start and/ or ending points of a number of events such as the marathon, walk and triathlon. Importantly, these were all strategic decisions made by stakeholders in order to leverage the iconic showcasing potential of the sport mega-event.

Relating to the infrastructure and regeneration projects linked to the event, the respondents mentioned that it is not merely the creation of these tangible structures that added to the nation brand reputation and image development, but most importantly, the design, aesthetic and iconographic elements of these developments.

\subsection{Leverage the event as a catalyst for susatainable development \& transformation:}

The respondents' experiences confirmed that a mega-event's perceived success is in large part attributed to the event-linked urban development projects, especially those aimed at improving crucial areas of urban and tourism infrastructure. Besides the stadia, private and public entities in the host cities and provinces invested heavily in building facilities and infrastructure or in urban rejuvenation projects. In both Cape Town and Durban, the areas from the fan park to the stadium precinct received an urban regeneration facelift. While many of these projects were public sector funded, there were also examples of private sector developments linked to the event. In Cape Town alone, five new five-star hotels were built in the lead up to the event - a significant boost to high-end tourist accommodation. There was evidence of this development even in the smaller host cities, with a stakeholder from Mbombela municipal area (Nelspruit) explaining that the city had benefited significantly from infrastructural development projects such as a new stadium, road and transport improvements and other tourism services developments. All of these developments were mentioned as contributing to the tourism, investment and overall nation branding legacy for the host nation.

However, not all of these examples have been positively sustained post the event, with some of the new stadia mentioned as particularly worrying examples of this. Some cities were mentioned as having leveraged the event opportunity more effectively than others. For example, Durban was mentioned as an example where the event-linked development and regeneration provided a boost to the city's tourism reputation. The stadium in Cape 
Town was mentioned as one that is not being utilised effectively enough and therefore not considered a sustainable legacy at the time of this study. Sustaining the stadia is therefore an important part of the event leveraging. This relates to economic viability of the stadia as well as their other potential usage and benefit for the host city. Examples of more effective post-event leveraging of stadia were given, such as: linking with multi-purpose, commercial activities, e.g. the stadium in Durban that features a bungee-jump, retail and restaurant attractions and has hosted a variety of other sport and charity-linked events. Beyond this, the stadia can also be leveraged as key domestic and international tourist attractions in their own right, forming part of the destination branding mix of the host cities. A stakeholder alluded to the challenge of leveraging the stadia, urging stakeholders to "think outside the box" (R23) with regards to the leveraging activities that can be undertaken.

\subsection{Sustain the momentum through post-event leveraging:}

Although acknowledging the positive impacts and leveraging activities detailed already, stakeholders also highlighted a number of missed opportunities and noted opportunities to leverage the branding impacts beyond the event period. All stakeholders noted the need for post-event leveraging, with some noting "a missed opportunity to keep the momentum going" and "not leveraging the benefits actively enough" (R5). For example, on-going media exposure was noted as "just as important as the positive publicity received during the tournament", and that "building on the momentum" that the World Cup provided was vital (R6). Leveraging the branding benefits was considered a challenge, with "much too little attention paid to post-tournament leverage" (R3), with possible reasons for this stated as "a lack of budgeting" or "because people were just exhausted at the end of the event" (R3). The same stakeholder (R3) noted the need to "gather the lessons learned" from the event as a possible platform for further leveraging of the benefits gained.

Some of the stakeholders were particularly critical at the lack of post-event leveraging, particularly within the tourism industry. They also offered potential solutions for leveraging from future events, relating to strategy, policy and actions that should be implemented. One stakeholder noted the need to "gather the lessons learned" (R3) from the event as a possible platform for further leveraging of the benefits gained. Another advocated that, "we need to put some actions in place to make sure we reap those rewards and benefits" (R19). The stakeholders certainly supported the need for a post-event strategy or master plan to leverage the post-event period. A useful recommendation made by two of the stakeholders was to view the event planning process as three distinct parts all of equal importance, namely the pre-event, during and post-event periods. Each of these periods requires adequate planning, budgeting and staffing to ensure that the opportunities are leveraged most effectively:

There should be some sort of a master plan that's associated with events and the master plan should revolve around the build-up to the event, managing the actual event and the managing of the warm-down strategy (R19).

Also relating to the aspect of planning, the respondents raised a concern regarding an over-emphasis on planning for the event's operational success at the expense of postevent leveraging. There was also emphatic agreement among the respondents that the positive experience of the 2010 mega-event should be sustained through the hosting of future events. While the type and scale of the event was not agreed upon, they indicated this as one of the key ways to leverage the nation branding legacy. The confidence gained 
through hosting a successful mega-event, the knowledge and skills developed as well as the infrastructure and the event planning in place were all reasons for this support. The success of the 2010 event was seen as enhancing the appeal of the nation as a host of future events, with one stakeholder referring to the "blueprint" for a future mega-event already being in place (R9). A useful recommendation made by a number of respondents was the call for a national events strategy to manage and carefully leverage the post-2010 period. Such a strategy should include a number of stakeholders that collectively decide upon the events that are beneficial for the nation and the objectives for each event that is hosted.

\section{DISCUSSION}

Smith (2014, p.16) proposed that sport mega-events be "reconceived as windows of opportunity within which to undertake initiatives". The respondents certainly showed an awareness of mega-events creating opportunities for a number of leveraging activities. From the findings it is clear that a wide variety of activities were planned for the preevent and event period to leverage the nation branding opportunity.

It appears that foremost in their view was the importance of the media. From the experiences of both 2010 and 2012 brand stakeholders, it is clear that there needs to be a management plan to cater for and host the new media forms as well as the traditional media representatives. It is evident that this process begins before the event, hosting media delegations and working with the media to source desirable studio locations that showcase iconic brand elements.

Although the literature acknowledges the vital role of the internal brand image component, the emphasis on the internal brand through mobilising the support of the local citizens was a more surprising leveraging emphasis by the stakeholders. However, given the more recent experience in Brazil (2014 FIFA World Cup hosts) where the local citizens orchestrated wide-scale protests against the event organisers and national government that at some stages threatened the event hosting, this emphasis seems justified. Indeed, the positive manner in which the local population embraced the 2010 mega-event was perceived as a powerful motivator of the new brand images for the nation through the event.

Brand ownership, leadership and control are noted as significant challenges within nation branding. There are a wide variety of stakeholders involved in or having a vested interest in the nation brand. Adding to this, for a mega-event there are a number of additional stakeholdrs involved, such as event rights owners, organising committees and sponsors.

While mega-events are commonly associated with urban development and regeneration projects, the findings indicated that a greater emphasis needs to be placed on the sustainability of these projects and the longer-term planning of their use, particularly in the case of the new stadia built for an event. Furthermore, from a branding perspective, the planning of these development schemes should consider design aspects. Montana et al. (2007) argued that design can be successfully used as a competitive differentiating factor for brands and the respondents noted that it was the design of many of the new facilities that helped to distinguish the 2010 event from previous hosts.

Despite these positive leveraging activities, there was general consensus that there was not much planning regarding post-event leveraging. While there was strong advocacy for post-event leveraging activities, there did not seem to be any sense of plan, strategy or urgency to do so. A lack of post-event leveraging therefore calls into question the longevity of nation branding gains for a host nation. 
The literature does not specifically mention the operational success of an event being a crucial element of perceived brand image success, although it is likely implied in the assessment of an event. Although the primary strategic focus for stakeholders during a mega-event is to ensure an operationally successful event, the respondents recommend that this should be the starting point for further leveraging of other brand legacies and not a detriment to the planning and implementation of legacy projects. Hosting future sport and non sport events, both mega-events and smaller events were mentioned as a key means to sustain the nation branding momentum, with a particular emphasis on a national events strategy.

\section{CONCLUSION}

This paper has explored the emerging discourse of nation branding in the context of sport mega-events and in particular the manner in which stakeholders can strategically leverage the opportunities created by these events for a host nation's brand. Although the important role of the media has been noted in previous impact studies, this study emphasises the planning of this and the engagement between stakeholders and the media, that begins well before the event period. It also emphasises the need to cater to a wider range of new and social media interests. The significant impact of the local citizens in the creation of a nation branding legacy from sport mega-events has perhaps been overlooked. Especially pertinent in light of the social protests surrounding the 2014 FIFA World Cup, this paper advocates strategic initiatives designed to communicate with the citizens and mobilise their support in the lead up to the event and during the event period.

While many studies have documented urban development and regenration through sport mega-events, this paper advises that these be considered within a sustainable development framework that considers the nation's strategic developmental objectives. The South African case also emphasises the role of authentic design and iconography as an important branding element that can be showcased through these developments. While the responses relating to the nation branding legacy for the 2010 mega-event host nation were very positive, the missed opportunities and lack of strategic planning to capitalise on these leaves a question mark over the longevity of these gains. Stakeholders are therefore urged to plan this process more deliberately in order to leverage the opportunity more effectively, before, during and, most importantly, after the event. Post-event leveraging should not be sidelined as a result of an over-emphasis on operational success. A national events strategy is proposed as a key post-event leveraging focus for stakeholders.

This paper therefore supports the emerging leveraging discourse. It is clear that the nation branding legacy for the host nation is a result of strategic activities and campaigns undertaken by a wide range of stakeholders before, during and post the event. The contention of this paper is that a nation branding legacy does not automatically occur for host nations. It is a combination of the opportunities provided by the sport mega-event and the strategic intention and activities of stakeholders. Although the focus on a specific case has allowed for an in-depth analysis of the particular context of this event, the inclusion of international experts and the reference to other international events and contexts leads the writers to propose the transferrability of these findings to other contexts, although particularly so among emerging nations with developing nation brands.

\section{REFERENCES}

Allmers, S. and Maennig, W. (2009), "Economic impacts of the FIFA Soccer World Cups in France 1998, Germany 2006, and outlook for South Africa 2010", Eastern Economic Journal, Vol. 35 No. 4, pp. 500-519. 
Anholt, S. (2003), Brand New Justice: The upside of global branding, ButterworthHeinemann, Oxford.

Anholt, S. (2007), Competitive Identity, Palgrave Macmillan, Hampshire.

Berkowitz, P., Germano, G., Gomez, L., and Schafer, G. (2007), "Brand China: Using the 2008 Olympic Games to enhance China's image", Place Branding and Public Diplomacy, Vol. 3 No. 2, pp. 164-178.

Chalip, L. (2004), "Beyond impact: A general model for sport event leverage", in Ritchie, B. W. and Adair, D. (Eds), Sport Tourism: Interrelationships, Impacts and Issues, Channel View Publications, Clevedon, pp. 226-247.

Chalip, L. and Costa, C.A. (2005), "Sport event tourism and the destination brand: Towards a general theory", Sport in Society, Vol. 8 No. 2, pp. 218-237.

Cornelissen, S. (2007), "Crafting legacies: the changing political economy of global sport and the 2010 FIFA World Cup ${ }^{\mathrm{TM}}$ ", Politikon, Vol. 34 No. 3, pp. 241-259.

Dickinson, J. and Shipway, R. (2007), Resource guide to the impact of events, The Higher Education Academy, Heslington.

Dinne, K. (2011), "The ethical challenge", in Morgan, N., Pritchard, A. and Pride, R. (Eds), Destination brands: Managing place reputation (3rd ed.), Butterworth-Heinemann, Oxford, pp. 69-80.

Donaldson, R., and Ferreira, S. (2009), "Re-creating urban destination image: Opinions of foreign visitors to South Africa on safety and security“, Urban Forum, Vol. 20, pp. 1-18.

Essex, S., and Chalkley, B. (1998), "Olympic Games: Catalyst of urban change", Leisure Studies, Vol. 17, pp. 187-206.

Fan, Y. (2010), "Branding the nation: Towards a better understanding", Place Branding and Public Diplomacy, Vol. 6 No. 2, pp. 97-103.

Florek, M., and Insch, A. (2011), "When fit matters: Leveraging destination and event image congruence", Journal of Hospitality Marketing and Management, Vol. 20, pp. 265286.

Getz, D. (2003), "Sport event tourism: Planning, development and marketing", in: Hudson, S., (ed), Sport and adventure tourism, Haworth, Binghampton, NY, pp. 49-88.

Gibson, H., Qi, C. and Zhang, J. (2008), "Destination image and intent to visit China, and the 2008 Beijing Olympic Games", Journal of Sport Management, Vol. 22 No. 3, pp. 427-450.

Grix, J. (2012), "Image leveraging and sports mega-events: Germany and the 2006 FIFA World Cup", Journal of Sport \& Tourism, Vol. 17 No. 4, pp. 289-312.

Hankinson, G. (2010), "Place branding research: A cross-disciplinary agenda and the views of practitioners", Place Branding and Public Diplomacy, Vol. 6 No. 4, pp. 300315 . 
Heslop, L. A., Nadeau, J., O’Reilly, N., and Armenakyan, A. (2013), “Mega-event and Country Co-branding: Image Shifts, Transfers and Reputational Impacts", Corporate Reputation Review, Vol. 16 No. 1, pp. 7-33.

Higham, J. and Hinch, T. (2009), Sport and tourism: globalisation, mobility and identity, Butterworth Heinemann, Oxford.

Jago, L., Dwyer, L., Lipman, G., Van Lill, D. and Vorster, S. (2010), "Optimising the potential of mega-events: an overview", International Journal of Event and Festival Management, Vol. 1 No. 3, pp. 220-237.

Mitchell, R.K., Agle, B.A., and Wood, D.J. (1997), "Toward a theory of stakeholder identification and salience: defining the principle of who and what really counts", The Academy of Management Review, Vol. 22 No. 4, pp. 853-886.

Montaña, J., Guzmán, F. and Moll, I. (2007), "Branding and design management: A brand design management model", Journal of Marketing Management, Vol. 23, No. 9-10, pp. 829-840.

Morgan, N., Pritchard, A. and Pride, R. (2010), Destination branding: creating the unique destination proposition, (Revised 2nd ed), Butterworth-Heinemann, Oxford.

Smith, A. (2014), "Leveraging sport mega-events: new model or convenient justification?", Journal of Policy Research in Tourism, Leisure and Events, Vol. 6 No. 1, pp. $15-30$.

Tomlinson, R., Bass, O., and Pillay, U. (2009). "Introduction", in Pillay, U., Tomlinson, R. and Bass, O., (Eds), Development and dreams: The urban legacy of the 2010 Football World Cup, Human Sciences Research Council, Cape Town, pp. 3-17.

Weed, M. (2009), "Progress in sports tourism research? A meta-review and exploration of futures", Tourism Management, Vol. 30 No. 5, pp. 615-628.

Weed, M. (2010), "Stakeholder perceptions in sport \& tourism", Journal of Sport \& Tourism, Vol. 15 No. 4, pp. 267-268.

Weed, M.E. and Bull, C.J. (2009), Sports Tourism: participants, policy and providers, (2nd ed.), Elsevier, Oxford. 